\title{
Role of bioactive molecules and maternal immune cells in breast milk in type 2 diabetes mellitus risk reduction
}

\author{
Tajudeen Olanrewaju Yahaya and Mutiu Oyekunle Sifau
}

\section{Article Info \\ Department of Biology, Federal Univer- sity Birnin Kebbi, Nigeria (TOY); Depart- ment of Cell Biology and Genetics, University of Lagos, Nigeria (MOS) \\ For Correspondence: \\ Tajudeen Olanrewaju Yahaya \\ yahaya.tajudeen@fubk.edu.ng \\ Received: \\ Accepted: \\ Available Online: \\ 2 June 2019 \\ 17 June 2019 \\ 1 July 2019}

ISSN: 2224-7750 (Online)

2074-2908 (Print)

DOI: $10.3329 /$ bsmmuj.v12i2.41683

Keywords: Adipokines; Breastfeeding Cytokines; Dibetes; Infant formula Obesity

Cite this article:

Yahaya TO, Sifau MO. Role of bioactive molecules and maternal immune cells in breast milk in type 2 diabetes mellitus risk reduction. Bangabandhu Sheikh Mujib Med Univ J. 2019; 12: 69-79.

Copyright:

The copyright of this article is retaine by the author(s) [Atribution CC-By 4.0]

Available at:

www.banglajol.info

A Journal of Bangabandhu Sheikh Mujib Medical University, Dhaka, Bangladesh
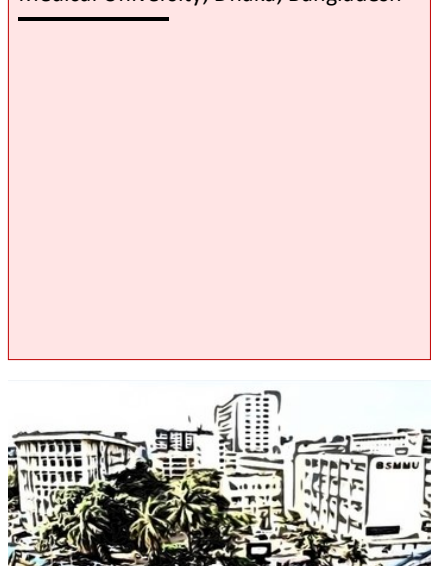

\section{Abstract}

Inadequate breastfeeding or its total neglect has been mentioned in several studies as a contributing factor to the globally rising incidence of Type 2 diabetes mellitus (T2DM). However, the anti-diabetic role of breast milk has not been given much attention. As such, this study was initiated to review and bring to update on the role of breastfeeding in the risk reduction of T2DM. Relevant information on the topic was retrieved from the reliable science databases, including PubMed, MedLine, Google Scholar, Researchgate, etc. The results showed that breast milk is not energy dense and contains several health-enhancing bioactive molecules, including adipokines, antimicrobial and growth factors, cytokines, nutrients, and immune cells. Adipokines interact with the central nervous system to modulate certain physiological processes involved in energy balance, thereby programming an infant to be at a reduced risk for overweight, obesity and T2DM later in life. The antimicrobial and growth factors, as well as immune cells and bioactive nutrients may stimulate the growth of beneficial bacteria and/or inhibit the growth of pathogens. Thus, strengthen neonate defense mechanisms to effectively prevent infections as well as short and longterm disorders such as obesity and T2DM. In conclusion, nursing mothers are advised to breastfeed babies adequately before introducing them to complementary foods. To cater to the need of babies who may not have access to breastfeeding, healthcare providers should formulate infant formula using breast milk components as basic constituents.

\section{Introduction}

Type 2 diabetes mellitus (T2DM) is a chronic and degenerative condition that disrupts blood glucose homeostasis. The disease begins either when the pancreatic $\beta$-cells produce too little insulin to maintain normal blood glucose ranges, or when the body fails to respond to the insulin produced. The immediate effect of T2DM is the high blood glucose level which, if allowed to persist for a long time, may lead to some complications involving multi-organ damage.1,2 The complications could be microvascular occurring in small blood vessels, e.g., retinopathy causing blindness, nephropathy resulting in kidney failure, and neuropathy leading to erectile dysfunction. $-3-5$ It could also be macro-vascular occurring in large blood vessels, e.g., cardiovascular disorders (such as heart-attacks and strokes), and severe foot ulcer resulting in amputation. $.3-5$

Due to its chronicity and complexity, DM exerts a huge socio-economic burden on the affected and the public, which collectively result in poor quality of life. $6-8 \mathrm{DM}$ is currently considered a global health threat consequence of its high morbidity and mortality rates, as well as huge budget, gulped yearly.. An estimated sum of $\$$
727 billion was spent on all types of DM in 2017 and the figure could reach about $\$ 776$ billion in the next few decades. 10 The costs accrued to T2DM management alone were projected to increase from $200 \%$ in 2012 to $600 \%$ in 2050.11 In terms of mortality, about 4 million deaths worldwide were attributed to DM in 2017 and over 21 million newborns ( 1 in 7 births) were affected by DM during fetal development. $\underline{12}$ These burdens are compounded by the rapidly rising prevalence of all forms of the disease. T2DM, in particular, has become one of the world's most prevalent and chronic non-communicable diseases. 9 Using mathematical models, its incidence rate was projected to rise from $16.7 \%$ in 2012 to as much as $37.7 \%$ in 2050.11 Numerically, around 425 million people were affected by the disease in 2017 and the figure was projected to rise to 629 million by $2045 . \underline{13}$ Another 352 million people were discovered to be pre-diabetic in the same year, which may lead to T2DM if left untreated.12

The rapidly rising incidence and burden of DM worldwide is suggestive of a widespread behavioral change, noticeably among which is change in breastfeeding patterns. Breastfeeding patterns changed worldwide following the introduction of complementary foods which 
Table I

Molecules in breast milk and their roles in type 2 diabetes mellitus

\begin{tabular}{|c|c|c|}
\hline & Examples & Core functions \\
\hline Adipokines & $\begin{array}{l}\text { Leptin, adiponectin, resistin, ghrelin, obestatin, } \\
\text { apelin, irisin, and nesfatin-1 }\end{array}$ & $\begin{array}{l}\text { Interact with central nervous system to modulate energy } \\
\text { homeostasis, insulin secretion, lipid metabolism as well } \\
\text { as boost beta cell performance and immunity }\end{array}$ \\
\hline Growth factors & $\begin{array}{l}\text { Epidermal growth factor, insulin-like growth } \\
\text { factor }\end{array}$ & $\begin{array}{l}\text { Regulate blood glucose level, improve beta cell mass } \\
\text { and pancreatic morphogenesis }\end{array}$ \\
\hline Bioactive nutrients & $\begin{array}{l}\text { Lactose, oligosaccharide, vitamins, minerals, } \\
\text { proteins (lactoferin, lysozyme, immunoglobulin }\end{array}$ & Anti-inflammatory, antimicrobial, immunomodulatory \\
\hline Cytokines & Interleukin 1, Interleukin 6, Interleukin 10 & $\begin{array}{l}\text { Anti-inflammatory, stimulate insulin synthesis, glucose } \\
\text { uptake }\end{array}$ \\
\hline Antimicrobial factors & $\begin{array}{l}\text { Oligosaccharide, Bifidobacterium genus and Lacto- } \\
\text { bacillus }\end{array}$ & Protect infection, boost gut immunity \\
\hline Polyunsaturated fatty acids & Docosahexaenoic acid, arachidonic acid & Lower blood glucose level, insulin resistence \\
\hline Maternal immune cells & Leukocyte, stem cell, mammary cell & Antimicrobial and immunomodulatory \\
\hline
\end{tabular}

came along with the industrial revolution in the 19th century. $\underline{14,15}$ Several studies had since outlined the health importance of breast milk and warned about the consequence of inadequate breastfeeding. Particularly, inadequate breastfeeding had been suggested as a contributing factor in the rising incidence of DM. However, the preventive role of breast milk in DM management has not been given the needed attention. To this end, this review was initiated to bring to the fore the importance of breast milk in the prevention of T2DM.

\section{Mechanistic links between breast milk and reduced T2DM}

Several studies have established the importance of breast milk in maintaining infants' health through to adulthood, specifically, in the prevention of metabolic diseases such as obesity and DM. Breast milk achieves these functions through regulation and programming of biological processes involved in energy homeostasis as well as immunomodulatory activities (Table I).

\section{Regulation and programming of biolo- gical processes involved in Energy Homeostasis}

The findings of many studies indicate that the central nervous system (CNS) may help the body regulate nutrient uptake, fat deposition, energy expenditure, and physiological activities in various tissues and organs. $16-18$ The CNS performs these functions with the assistance of adipokines, including leptin, adiponectin, resistin, ghrelin, obestatin, apelin, irisin, and nesfatin-1 as well as some substances such as polyunsaturated fatty acids (PUFAs). $.19,20$ These bioactive molecules have been reportedly found in breast milk, which underscores the importance of breast milk in shaping biological events that maintain energy balance in newborns through to adulthood. 16,18 Thus, breast milk may help program an infant to be at a reduced risk for overweight, obesity and T2DM later in life.21-23 Each of these bioactive molecules in breast milk performs specific or related functions, which are outlined below along with the role played by breast milk's low-calorie nutrients.

\section{Leptin}

Leptin is a 167-amino-acid protein encoded by obese gene and synthesized by the adipocytes. $\underline{24,25}$ The hormone plays a vital role in energy balance by regulating food intake (reduces appetite) and communicating the brain the amount of fat stored in various tissues and organs. $\frac{18,25}{25}$ Leptin improves insulin sensitivity, reducing intracellular glucose and lipid levels in skeletal muscle, liver, and pancreatic $\beta$-cells.18, 26 Other functions of leptin include regulation of immune and inflammatory responses as well as in the formation of new blood vessels (angiogenesis). .27 Leptin carries out these functions under physiological states by attaching to certain receptors embedded in the brain and peripheral tissues and organs. $\frac{18,24}{24}$ Outside the normal range, leptin may cause hyperphagia and decreased energy expenditure, resulting in obesity, insulin resistance, T2DM, among others. $\underline{24}$ Fortunately, leptin levels in breast milk reduce with time as lactation progresses and correlates significantly with other maternal hormones. .28

\section{Adiponectin}

Adiponectin enhances glucose metabolism and insulin effectiveness in the liver as well as increases insulin sensitivity by inducing glucose uptake and fat oxidation in the skeletal muscle. 29,30 Adiponectin functions right from childhood and its serum concentration is directly proportional to growth parameters, adiposity, and leptin levels. 18 As such, adi- 
ponectin may prevent the development of obesity and T2DM.31 Depletion of adiponectin levels has been linked with insulin resistance, while adiponectin supplementation by diabetics enhances insulin sensitivity. $\underline{18}$ Aside from energy balancing, adiponectin is an anti-inflammatory molecule, which blocks reactive oxygen species, enhancing the expression of an anti-inflammatory cytokine, interleukin 10 (IL-10). 32 , 33 It may also inhibit NF-KB inflammatory signaling pathway and suppress tumor necrosis factor a (TNF-a) inflammatory reactions. $\underline{32,33}$ These show adiponectin doubles as an immune booster.

\section{Resistin}

Among all the adipokines in breast milk, resistin is different in that its action on glucose metabolism opposes insulin's action on glucose. $\underline{18}$ While insulin represses resistin synthesis, resistin induces insulin resistance- the activity from which resistin derived its name. 18,34 Resistin level in breast milk decreases as lactation progresses and correlates with circulating levels of various reproductive and metabolic hormones, which could account for its anti-diabetic property. $.35 \mathrm{~A}$ drop in the serum level of the hormone has been observed in individuals with T2DM following exercise and certain diets, improving insulin sensitivity and glucose tolerance. 34 This suggests that lack of exercise and overproduction of resistin may be involved in the onset of T2DM. $\underline{34}$ To this end, elevated plasma resistin has been shown to contribute to the impaired glucose tolerance and insulin resistance observed in T2DM through adiposity and its pro-inflammatory properties. $.34,36$ However, high serum resistin could be beneficial during fetal development by enhancing glucose production in the liver, preventing hypoglycemia after birth. 18

\section{Ghrelin}

Ghrelin is a 28-amino acid growth hormone releasing peptide, which increases body weight and adiposity by acting on the hypothalamic melanocortinergic system. $\frac{37}{6}$ Ghrelin is involved in fetal growth and development as it is found in cord plasma from 30 weeks into pregnancy. 18 The hormone also stimulates appetite, fat deposition and rapid growth after a period of growth retardation, and its serum levels correlate with growth parameters in newborn through to infancy. $.18,38$ As a result of its appetite inducing property, it is referred to as hunger hormone. $\underline{38}$ Aside ghrelin's appetite and adiposity-inducing properties, it also helps maintain energy balance by stimulating a marked rise in plasma glucose concentrations, accompanied by a drop in insulin production. 18,38 Ghrelin may also act as a paracrine signaling molecule in the pancreas, enhancing $\beta$-cell performance. $\frac{39}{2}$ Loss of this function due to mutation in ghrelin precursor has been linked with insulin resistance. 39 Additionally, ghrelin exerts anti-oxidant and anti-apoptotic effects on endothelial and nervous tissue, preven- ting diabetes-related diseases. $\underline{39}$ Ghrelin levels have been demonstrated to be reduced in several metabolic disorders, including obesity and T2DM. $\underline{40}$

\section{Obestatin}

Obestatin is a 23-amino acid polypeptide encoded by ghrelin gene and is produced from post translational modification of preproghrelin, which is a precursor of ghrelin. $\underline{41,42}$ However, it works oppositely to ghrelin on food intake and plays a role in energy balance. $\underline{43}$ Obestatin suppresses appetite, thus lessen food and water consumption as well as body weight gain and movement of foods through the digestive system. $\underline{44,45}$ The hormone has also been shown to increase $\beta$-cell mass, adipogenesis and lipid metabolism by up-regulating genes associated with $\beta$-cell regrowth, insulin synthesis and adipogenesis. $.44 \mathrm{~A}$ reduction in serum concentrations of obestatin as well as repression of its putative receptor named GPR39 have been reported in individuals with obesity and T2DM. $\underline{46}$ Obestatin supplementation in diabetic rats was observed to greatly reduce plasma glucose levels and insulin resistance compared with non-treated rats in a study. .47 This suggests obestatin can help to regulate blood glucose level and when combined with other materials with similar therapeutic effects, can be used to treat obesity and T2DM. .77

\section{Apelin}

Apelin has been shown to boost insulin sensitivity and inhibit obesity-related disorders, $\underline{48}$ possibly through body fluid and energy homeostasis. $\underline{49}$ The hormone is a peptide of a 12-amino acid, encoded by the APLN gene and embedded in human adipocytes. 50 Apelin can exist in several active forms, including apelin-36, apelin-17, apelin-13 and apelin12.51 Apelin controls fetal and neonatal glucose homeostasis, which can be disrupted by fetal growth retardation in malnourished mothers. 52 Apelin enhances glucose and lipid metabolism as well as modulates insulin secretion. $\underline{53-55}$ However, deficiency and high plasma concentrations of the adipokine have been observed in individuals with obesity and T2DM. $\underline{54,56,57}$ This suggests that deficiency and over secretion of the hormone may be associated with the two mentioned diseases.

\section{Irisin}

Irisin is a myokine regulated by exercise and has been demonstrated to increase the energy expenditure by the browning of white adipose tissues. $\underline{.5-60}$ White adipocytes store energy, while brown adipocytes consume it, allowing the body to prevent fat accumulation, culminating in weight loss. $.61,62$ At the same time, irisin is an adipokine, secreted by the white adipose tissues, $\underline{\underline{6}}$ and elevated levels of irisin may enhance glucose homeostasis in a number of ways. These include reduction of insulin resistance, boosting of insulin receptors in skeletal muscle, enhancing hepatic glucose and lipid metabolism as 
well as promoting pancreatic $\beta$-cell functions..$\underline{60,64,65}$ Reduction of insulin resistance is achieved indirectly through lowering of fasting insulin.66 In a Japanese study, the serum level of irisin was positively correlated with insulin resistance in individuals with obesity. .67 The scientists opined that the irisin enhancement could be a compensatory secretion in response to insulin resistance. $\underline{67}$

\section{Nesfatin-1}

Nesfatin-1 is calcium and DNA binding peptide embedded in the central and peripheral nervous system as well as peripheral tissues such as digestive organs and adipose tissues. $.68,69$ Nesfatin- 1 has many chemical messengers, which help it to reduce appetite independent of leptin, controlling body weight, energy homeostasis as well as increasing insulin secretion. 68,70 Nesfatin- 1 has been demonstrated to achieve these functions by inhibiting darkphase food intake. $\underline{71}$ Additionally, nesfatin-1 enhances $\beta$-cell performance under hyperglycemic conditions, modulates gastrointestinal motility, improves glucose and lipid metabolism, $\underline{72,73}$ and influences the brain to control insulin sensitivity. $\underline{74}$ However, high level of nestatin-1 has been reported in newly diagnosed T2DM patients, which was reduced following treatment with anti-diabetic drugs. $\underline{.1}$ This suggests that over secretion of the hormone may induce T2DM. Impaired synthesis or release of this adipokine has also been reported among pregnant women with gestational diabetes. .55

\section{PUFAs}

PUFAs are fatty acids consisting of two families, namely $n-3$ and $n-6$ fatty acids, each with distinct biological activities. $\underline{76}$ The $\mathrm{n}-3$ family includes alphalinolenic acid, eicosapentaenoic acid, and docosahexaenoic acid while the n-6 family includes linolenic acid and arachidonic acid. .77 PUFAs play a key role in maintaining normal cell function and its deficiency or disruption of its metabolism may cause several metabolic disorders. .77 In particular, long chain polyunsaturated fatty acid can reduce fasting plasma glucose levels, insulin resistance and, thus, decrease the risk of T2DM. $.78,79$ Studies have shown that breast-fed infants have markedly higher concentrations of docosahexaenoic acid in their erythrocytes and brain cortex than formula-fed infants, $\underline{\underline{80}}$ indicating that breast milk contains a great amount of the fatty acid. Low concentrations of docosahexaenoic acid and other long chain polyunsaturated fatty acids in skeletal muscle membrane phospholipids have been demonstrated to aggravate insulin resistance and obesity in adults. $\underline{78}$ Additionally, omega-3PUFAs supplementation has been shown to reduce insulin resistance and blood lipids in individuals with a high risk of T2DM. 81 In a study in which dietary carbohydrate was substituted with saturated fat, there was no appreciable effect on blood glucose regulation. $\underline{.2}$ However, when carbohydrate and saturated fat were replaced with a diet rich in polyunsaturated fat, a significant glycemic control was achieved. 82 This suggests that consuming more unsaturated fats instead of carbohydrates or saturated fats will improve blood glucose control. 82

\section{Low calorie nutrients}

Lactose accounts for about $40 \%$ of calories in breast milk, while fat provides around $50 \% . \underline{.8}$ This suggests that the remaining $10 \%$ is provided by other nutrients in breast milk, including proteins, vitamins and minerals. Compared to infant formula, breast milk contains significantly lower quantities of protein and energy, causing breast-fed babies to grow moderately. $\underline{16,84}$ These nutritional properties of breast milk may program breast-fed babies to less dense diets later in life, resulting in moderate body weight. $\underline{5}$ High protein intakes during infancy accelerate growth and increase fat mass,, 86 culminating in high body mass index (BMI) later in adulthood.16 Low protein consumptions may also lead to less insulin production with resultant less fat storage, preventing obesity as well as the proliferation of adipocytes. 86,87 Additionally, breastfeeding may enable babies to learn to control the amount of diet consumed, programming them to naturally regulate energy intake later in life. .87

\section{Immunomodulating activities}

Some molecules in breast milk may strengthen the neonatal immune system through to adulthood to effectively contain several diseases, including obesity and T2DM. These molecules include antimicrobial factors, cytokines, growth factors, bioactive nutrients and maternal immune cells. $.88,89$

\section{Antimicrobial factors}

The antimicrobial factors in breast milk include glycans such as oligosaccharides, which is synthesized from lactose in the mammary gland and is often referred to as human milk oligosaccharides. $\underline{8-}$ 90 Oligosaccharides are abundant in breast milk and protect infants from microbial infection by blocking microorganisms from binding to the intestinal mucosa through the production of bacteriocins and organic acids. 90 Oligosaccharides may also modulate the immune system by repressing certain proinflammatory genes. 90 Additionally, oligosaccharides are involved in cellular communication and cell-to-cell recognition activities as well as stimulating and enriching the gut microbiota with beneficial bacteria.90 In an experiment in which intestinal epithelial cells and HeLa cells were treated with oligosaccharides, differential expressions of certain cytokines were observed. 91 While the levels of some pro-inflammatory cytokine were reduced, cytokines involved in tissue repair and energy balance were enhanced. Aside oligosaccharides, breast milk naturally contains beneficial microbes, particularly Bifidobacterium genus and Lactobacillus as well as Streptococcus and Staphylococcus, all which may 
populate neonate gut, strengthening it against harmful microbes. 92 The breast milk microbes may also stimulate anti-inflammatory activities through the production of certain cytokines, reducing several inflammatory diseases, $\underline{\underline{93}}$ including T2DM later in life.

\section{Cytokines}

Some of the cytokines in breast milk that are important to obesity and T2DM pathogenesis and prevention include interleukin 1 (IL-1), interleukin 6 (IL-6), and interleukin 10 (IL-10). IL-1 is a group of proinflammatory cytokines and high concentrations of it have been linked with obesity, disruption of proinsulin synthesis, and $\beta$-cell apoptosis. 94 However, at moderate concentrations, IL-1 stimulates proinsulin synthesis, thereby decreasing circulating blood sugar levels.95 Moreover, the IL-1 family has an ant-inflammatory member, named interlocking 37 (IL-37), $\underline{96}$ and has been demonstrated to prevent obesity-induced inflammation and insulin resistance. 97

Although interleukin-6 (IL-6) is a known proinflammatory cytokine, $\underline{98}$ it also takes part in antiinflammatory activities involving neuronal function and development.99 IL-6 is secreted by several tissues, particularly adipose tissue and, at high concentrations, may induce insulin resistance, obesity and T2DM. 98,100 However, the presence of IL-6 is normal and, acute administration of it, has been shown to improve insulin resistance and mediate glucose uptake.98, 101 Breast milk IL-6 concentration has been demonstrated to have negative associations with infant growth parameters and adiposity. .02 Moreover, IL-6 may be anti-inflammatory by enhancing the production of other anti-inflammatory cytokines such as IL-1ra and IL-10 while suppressing the synthesis of the pro-inflammatory cytokine TNF- $a .103$

IL-10 is an anti-inflammatory cytokine that inhibits pro-inflammatory cytokines while up-regulating the anti-inflammatory ones. IL-10 is thought to prevent aging-related inflammation, insulin resistance in skeletal muscle, and T2DM.104, 105 According to Hong et al. (2009), 106 IL-10 enhances insulin sensitivity, prevents infiltration of skeletal muscle by obesity-associated macrophages, and suppresses pro-inflammatory cytokines along with their inhibitory actions on insulin signaling and glucose metabolism. IL-10 is so important, its under-expression has been shown to play a key role in severe inflammatory diseases such as T2DM. 104

The most abundant cytokine in breast milk is the transforming growth factor beta (TGF- $\beta$ ), which belongs to the transforming growth factor superfamily.107 Members of this cytokine family include TGF- $\beta 1$ to $\beta 4$ as well as activins, bone morphogenetic proteins, growth and differentiation factors, among others. 107,108 Several studies have shown that TGF- $\beta$ family ligands can regulate glucose homeos- tasis by enhancing $\beta$-cell function and, in adults, can boost $\beta$-cell mass or accumulation from progenitors. 109,110 These ligands can also be influenced by their soluble antagonists to maintain glucose homeostasis. $\underline{109,110}$

\section{Growth factors}

Epidermal growth factor (EGF) and insulin-like growth factor (IGF) are the two major breast milk growth factors 111 with anti-diabetic properties. EGF is synthesized in the pancreas $\underline{112}$ and has been shown to enhance the proliferation of diverse cells. $\underline{113,114}$ Specifically, some members of the EGF family are being suspected to be involved in the development of the pancreas.112 In an experiment, EGF increased insulin secretion in mouse pancreatic islets and in a pancreatic $\beta$-cell line within a short duration, while diabetic animals were shown to be deficient of EGF.112 In another study, EGF increased plasma insulin levels and lowered blood glucose levels in healthy and diabetic mice.112 Additionally, epidermal growth factor receptor is massively expressed in the pancreas of developing human fetus, and mice deficient of the receptor has been demonstrated to show malfunctioned pancreatic islets. .115

IGF is a superfamily comprising of IGF-I, IGF-II, insulin-like growth factor binding proteins (IGFBPs) and insulin-like growth factor specific proteases (IGFSP).116 Nearly half of the IGF-I amino acid sequence resembles that of insulin and produces almost the same blood glucose lowering effect. .117 However, experimental findings have shown that deficiency and overproduction of IGF-I can disrupt glucose metabolism and increase T2DM risk. $\underline{117,118}$ Normal levels of IGF-binding protein-2 (IGFBP-2) promotes glucose metabolism and inhibits the pathogenesis of obesity and insulin resistance, $\underline{119,120}$ while its deficiency has been implicated in some metabolic disorders. 121

Bioactive nutrients (carbohydrates, fatty acids, minerals, vitamins and proteins)

Aside from nutritional provision, some nutrients are bioactive and so may serve some other functions. Lactose and, oligosaccharides discussed earlier, are the main carbohydrates in breast milk르 and lactose has been shown to deliver noninsulinogenic carbohydrate to infants. $\underline{8}$ This unique form of carbohydrate gradually metabolizes to glucose in the liver as well as enhancing fatty acid oxidation, thus helps to maintain glucose and insulin balance. $\underline{83}$ Moreover, lactose inhibits the proliferation of harmful gut bacteria, while stimulating the growth of beneficial ones, resulting in improved calcium, phosphorus and magnesium absorption.123 Long chain polyunsaturated fatty acids, discussed earlier, protect $\beta$-cells from the cytotoxic effects of alloxan. $\underline{78}$ Long-chain polyunsaturated fatty acids also inhibit inflammatory activities of TNF-a, which may explain the bene- 
ficial effect of long-chain polyunsaturated fatty acids in both T1DM and T2DM. $\underline{7}$ Additionally, breast milk contains sufficient quantities of most vitamins and minerals for optimum growth and development of infants, except for vitamins D and K. .123 Minerals play key roles in many physiological functions of breast milk, forming essential parts of many enzymes and are of biological importance to molecules and structures. $\underline{123}$

Breast milk contains several bioactive proteins whose bioactivities include enzyme activities, boosting of nutrient absorption, growth stimulation, strengthening of the immune system and antimicrobial activities.124 Some of the bioactive proteins in breast milk include lactoferrin, lysozyme, secretory immunoglobulin A (sIgA), haptocorrin, bile salt stimulated lipase, $\beta$ - and $\mathrm{K}$-casein, among others.124 Majority of these bioactive factors are abundant in breast milk and stimulate immunomodulatory, antiinflammatory, and antimicrobial activities in neonates. $.52,122$ The mentioned bioactive factors employ several mechanisms in their antimicrobial activities, including proliferation of beneficial microorganisms and phagocytosis or inhibition of proliferation of harmful microorganisms. $\underline{124}$ The bioactive factors may also devise some other mechanisms that prevent attachment or invasion of harmful microorganisms. 124 For example, lactoferin can inhibit pathogens by binding to iron and making it inaccessible to pathogens which require iron to grow, thus preventing infection as well as inflammatory disorders. $\underline{124,125}$

\section{Maternal immune cells}

Several studies have shown that breast milk contains abundant maternal immune cells, which modulate neonatal immunity through to adulthood, preventing diseases such as obesity and T2DM. These maternal cells include immune cells (leukocytes), stem cells, and mammary cells released from breast tissue.126 The leukocytes are far more abundant in colostrum and include neutrophils, macrophages and lymphocytes; each with the distinct role, but work synergistically to fight infections. Newborns consume nearly 100 million maternal cells daily, mostly leukocytes.127 Leukocytes inhibit harmful microbes in the breast while at the same time populate baby's gut microbiota and strengthen its defense mechanism. $\underline{127,128}$ Most of the leukocytes in breast milk are neutrophils, which decline from six weeks after birth, protecting breast and the infant from infections. 129 The second most abundant immune cell in breast milk is the macrophage, accounting for about $40 \%$ of the leukocytes in colostrum and is phagocytic like the neutrophils.129 In the gut, macrophages synthesize and up-regulate lysozyme as well as stimulate lymphocytes against pathogens. 129 The third mentioned immune cell, lymphocyte, produces several immune-boosting chemicals such as gamma-interferon, migration inhibition factor and monocyte chemotactic factor. $\underline{129}$

Another immune cell named innate lymphoid cell has also been isolated in breast milk.127 It may occupy the gut of newborns temporarily, protecting the baby from pathogens and inflammation as well as training its immature immune system and modulating its gut microbiota. 127 Innate lymphoid cell is unique in that it does not directly fight infections. Instead, it senses inflamed cells in infected tissues and through cellular signaling communicate and coordinate other immune cells to swing into action. $\underline{127}$

\section{Formulation of Infant Formula using Breast milk as a Baseline}

The busy schedules of some nursing moms and some health issues have frequently denied some babies access to breastfeeding, and has necessitated the manufacturing of several infant formulas. However, for babies of such moms to enjoy the same benefits as naturally breast-fed infants, infant formula must be formulated based on the bioactive substances and nutrients in breast milk. Key messages from this review, which may serve as guides for formulating infant formula are summarized below:

1. An infant formula should contain low calorie and nutritional protein. $.66,87$

2. The formula should contain adipokines such as leptin, adiponectin, resistin, ghrelin, obestatin, apelin, irisin, and nesfatin- 1 as well as PUFAs. $\underline{19,20}$ However, leptin, $\underline{\underline{4}}$ resistin $\underline{34}$ apelin, $\underline{54,56,57}$ and nesfatin-1 11 should not exceed the normal physiological range.

3. Antimicrobial factors such as oligosaccharides $88-90$ as well as some naturally beneficial bacteria such as Bifidobacterium genus and Lactobacillus, among others, 22 should be included in the formula.

4. The formula should also contain moderate quantities of some pro-inflammatory cytokines, including IL-195 and IL-6, $\underline{98}$ and abundant anti-inflammatory cytokines such as IL-10, $\underline{104}$ IL-37,, 97 and TGF- $\beta \cdot \underline{107}$

5. Some growth factors, particularly EGF and IGF (e.g. IGF-1 and IGFBPs) should be added, 111 howver, IGF-1 should be kept at a physiological range. $\underline{117,118}$

6. The formula must also contain abundant bioactive nutrients such as lactose $\underline{122}$ as well as some major vitamins and minerals. $\underline{123}$ Some bioactive proteins such as lactoferrin, lysozyme, sIgA, haptocorrin, bile salt stimulated lipase, $\beta$ - and $\mathrm{k-}$ casein, among others, 124 should also be included. 


\section{Conclusion}

From the literature reviewed, it is clear that breast milk contains abundant bioactive molecules and nutrients. These substances protect newborns from infections and inflammation as well as train the immune system of infants, preventing short and long-term diseases such as obesity and T2DM, among others. Nursing mothers are, therefore, advised to breastfeed their babies adequately, at least six months, before introducing complementary foods. Healthcare providers, particularly nutritionists, are also advised to formulate infant formula using breast milk as standard, to satisfy the needs of babies who may not have access to breastfeeding. Moreover, breast milk is dynamic and its quality and quantity depend on several internal and external factors. As such, for babies to derive maximum benefits from breastfeeding, nursing mothers should eat balanced diets, keep personal hygiene and be emotionally and psychologically stables. Breast milk is also deficient of some vitamins, particularly vitamins $\mathrm{D}$ and $\mathrm{K}$, so exclusive breastfeeding should be done with vitamin supplementation with the advice of a qualified personnel.

\section{Conflict of interest}

The authors have no conflicting interest to declare.

\section{References}

1. Center for Disease Control and Prevention. More than 100 million Americans have diabetes or prediabetes. CDC Report 2017. Available online from https://www.cdc.gov/media/releases/ 2017/p0718-diabetes-report.html

2. World Health Organization. Diabetes Factsheets 2018. Available online from https://www. who.int/news-room/fact-sheets/detail/diabetes

3. Amon SK, Aikins MKS. Economic burden of type 2 diabetes mellitus complications among patients in the eastern region of Ghana: A descriptive cross-sectional cost-of-illness study. Diabetes Manag. 2017; 7: 367-76.

4. Rangel, ÉB, Rodrigues CO, de Sá JR. Micro- and macrovascular complications in diabetes mellitus: Preclinical and clinical studies. J Diabetes Res. 2019; 2019.

5. Piemonte L. Diabetes glossary. International diabetes Federation 2019. Available online from https://idf.org/52-about-diabetes.html

6. Dall TM, Zhang Y, Chen YJ, Quick WW, Yang WG, Fogli J. The economic burden of diabetes. Health Affairs. 2010; 29: 297-303.

7. Nisar MU, Asad A, Waqas A, Ali N, Nisar A, Qayyum MA, Maryam H, Javaid M, Jamil M. Association of diabetic neuropathy with duration of type 2 diabetes and glycemic control. Cureus 2015; 7: e302-02.

8. Cammon A, Handelsman Y, Heile M, Shannon M. Burden of illness in type 2 diabetes mellitus. J Manag Care Spec Pharm. 2018; 24: S5-S13.

9. Afroz A, Alramadan MJ, Hossain MN, Romero L, Alam K, Magliano DJ, Billah B. Cost-of-illness of type 2 diabetes mellitus in low and lower-middle income countries: A systematic review. BMC Health Services Res. 2018; 18: 972.

10. Baron C. Estimated global healthcare expenditure to treat diabetes in 2017 and 2045 (in billion U.S. dollars). Statista 2019. Available online from https://www.statista.com/statistics/241820/ estimated-global-healthcare-expenditures-to-treat -diabetes/

11. Awad SF, O'Flaherty M, Critchley J, Abu-Raddad LJ. Forecasting the burden of type 2 diabetes mellitus in Qatar to 2050: A novel modeling approach. Diabetes Res Clin Pract. 2018; 137: 10008

12. Piemonte L. Diabetes facts and figures. IDF Diabetes atlas. 8th ed. 2017. Available online from https://idf.org/52-about-diabetes.html

13. Forouhi NG, Misra A, Mohan V, Taylor R, Yancy $\mathrm{W}$. Dietary and nutritional approaches for prevention and management of type 2 diabetes. BMJ. 2018; 361: k2234.

14. Castilho SD, Barros Filho AA. The history of infant nutrition. J Pediatr (Rio J) 2010; 86: 179-88.

15. Papastavrou M, Genitsaridi SM, Komodiki E, Paliatsou S, Kontogeorgou A, Iacovidou N. Breastfeeding in the course of history. J Pediatr Neonatal Care. 2015; 2: 00096.

16. Faulconbridge LF, Hayes MR. Regulation of energy balance and body weight by the brain: A distributed system prone to disruption. Psychiatr Clin North Am. 2011; 34: 733-45.

17. Savino F, Liguori SA, Fissore MF, Oggero R. Breast milk hormones and their protective effect on obesity. Int J Pediatr Endocrinol. 2009; 2009: 327505 .

18. Savino F, Liguori SA, Sorrenti M, Fissore MF, Oggero R. Breast milk hormones and regulation of glucose homeostasis. Int J Pediatr 2011; 2011: 803985 .

19. Çatlı G, Dündar NO, Dündar BN. Adipokines in breast milk: An update. J Clin Res Pediatr Endocrinol. 2014; 6: 192-201.

20. Mamdouh M, Shaban S, Ibrahim Abushouk A, Zaki MM, Ahmed OM, Abdel-Daim MM. Adipokines: Potential therapeutic targets for vascular dysfunction in type II diabetes mellitus and obesity. J Diabetes Res. 2017; 2017.

21. Savino F, Benetti S, Liguori SA, Sorrenti M, Cordero Di Montezemolo L. Advances on human milk hormones and protection against obesity. 
Cell Mol Biol. 2013; 59: 89-98.

22. Pereira PF, Alfenas RDC, Araújo RM. Does breastfeeding influence the risk of developing diabetes mellitus in children? A review of current evidence. J Pediatr (Rio J). 2014; 90: 7-15.

23. Horta BL, Mola CL, Victora CG. Long-term consequences of breastfeeding on cholesterol, obesity, systolic blood pressure and type 2 diabetes: A systematic review and meta-analysis. Acta Paediatrica. 2015; 104.

24. Tsai JP. The association of serum leptin levels with metabolic diseases. Tzu Chi Med J. 2017; 29: 19296.

25. Facey A, Dilworth L, Irving R. A review of the leptin hormone and the association with obesity and diabetes mellitus. J Diabetes Metab. 2017; 8: 727.

26. Dyck DJ. Adipokines as regulators of muscle metabolism and insulin sensitivity. Appl Physiol Nutr Metab. 2009; 34: 396-402.

27. Wasim M. Role of leptin in obesity. J Obes Weight Loss. 2015; 5: 258.

28. IlcoI YO, Hizli ZB, Ozkan T. Leptin concentration in breast milk and its relationship to duration of lactation and hormonal status. Int Breastfeed J. 2006; 1: 21.

29. Kadowaki T, Yamauchi T, Kubota N, Hara K, Ueki K, Tobe K. Adiponectin and adiponectin receptors in insulin resistance, diabetes, and the metabolic syndrome. J Clin Invest. 2006; 116: 1784 -92 .

30. Achari AE, Jain SK. Adiponectin, a therapeutic target for obesity, diabetes, and endothelial dysfunction. Int J Mol Sci. 2017; 18: 1321.

31. Wang Y, Meng RW, Kunutsor SK, Chowdhury R, Yuan JM, Koh WP, Pan A. Plasma adiponectin levels and type 2 diabetes risk: A nested casecontrol study in a Chinese population and an updated meta-analysis. Sci Rep. 2018; 8: 406.

32. Ouchi N, Walsh K. Adiponectin as an antiinflammatory factor. Clinica Chimica Acta. 2007; 380: 24-30.

33. Nigro E, Scudiero O, Sarnataro D, Mazzarella G, Sofia M, Bianco A, Daniele A. Adiponectin affects lung epithelial A549 cell viability counteracting TNFa and IL-1ß toxicity through AdipoR1. Int J Biochem Cell Biol. 2013; 45: 1145-53.

34. Cobbold C. Type 2 diabetes mellitus risk and exercise: Is resistin involved? J Sports Med Phys Fitness. 2019; 59: 290-97.

35. Ilcol YO, Hizli ZB, Eroz E. Resistin is present in human breast milk and it correlates with maternal hormonal status and serum level of C-reactive protein. Clin Chem Lab Med. 2008; 46: 118-24.

36. Chen BH, Song $\mathrm{Y}$, Ding EL, Roberts CK, Manson JE, Rifai N, Buring JE, Gaziano JM, Liu S. Circu- lating levels of resistin and risk of type 2 diabetes in men and women: Results from two prospective cohorts. Diabetes Care. 2009; 32: 329-34.

37. Poher AL, Tschöp MH, Müller TD. Ghrelin regulation of glucose metabolism. Peptides 2018; 100: 236-42.

38. Pradhan G, Samson SL, Sun Y. Ghrelin: Much more than a hunger hormone. Curr Opin Clin Nutr Metab Care. 2013; 16: 619-24.

39. Banks KA, Murphy KG. Role of ghrelin in glucose homeostasis and diabetes. Diabetes Manag. 2013; 3: $171-82$.

40. Pöykkö SM, Kellokoski E, Hörkkö S, Kauma H, Kesäniemi YA, Ukkola O. Low plasma ghrelin is associated with insulin resistance, hypertension, and the prevalence of type 2 diabetes. Diabetes 2003; 52: 2546-53.

41. Lacquaniti A, Donato V, Chirico V, Buemi A, Buemi M. Obestatin: An interesting but controversial gut hormone. Ann Nutr Metab. 2011; 59: 193-99.

42. Szentpéteri A, Lőrincz H, Somodi S, Varga VE, Paragh G, Seres I, Harangi M. Serum obestatin level strongly correlates with lipoprotein subfractions in non-diabetic obese patients. Lipids Health Dis. 2018; 17: 39.

43. Zizzari P, Longchamps R, Epelbaum J, Bluet-Pajot MT. Obestatin partially affects ghrelin stimulation of food intake and growth hormone secretion in rodents. Endocrinology 2007; 148: 1648-53.

44. Cowan E, Burch KJ, Green BD, Grieve DJ. Obestatin as a key regulator of metabolism and cardiovascular function with emerging therapeutic potential for diabetes. Bri J Pharmacol. 2016; 173: $2165-81$

45. Zhang MY, Li F, Wang JP. Correlation analysis of serum obestatin expression with insulin resistance in childhood obesity. Genet Mol Res. 2017; 16: gmr16029210.

46. Kolodziejski PA, Pruszynska-Oszmalek E, Sassek M, Kaczmarek P, Szczepankiewicz D, Billert M, Mackowiak P, Strowski MZ, Nowak KW. Changes in obestatin gene and gpr39 receptor expression in peripheral tissues of rat models of obesity, type 1 and type 2 diabetes. J Diabetes. 2017; 9: 353-61.

47. Latif N, Hussain MM, Khan MA. Effect of obestatin on glucose homeostasis, insulin resistance and serum 1 in type 2 diabetic rats. Pakistan Armed Forces Med J. 2018; 68: 998-1002.

48. Dray C, Knauf C, Daviaud D, Waget A, Boucher J, Buléon M, Cani PD, Attané C, Guigné C, Carpéné C, Burcelin R. Apelin stimulates glucose utilization in normal and obese insulin-resistant mice. Cell Metab. 2008; 8: 437-45.

49. Wysocka MB, Pietraszek-Gremplewicz K, Nowak D. The role of apelin in cardiovascular diseases, obesity and cancer. Front Physiol. 2018; 9: 557. 
50. Castan-Laurell, Dray C, Knauf C, Kunduzova O, Valet P. Apelin, a promising target for type 2 diabetes treatment? Trends Endocrinol Metab. 2012; 23: 234-41.

51. Mesmin C, Fenaille F, Becher F, Tabet JC, Ezan E. Identification and characterization of apelin peptides in bovine colostrum and milk by liquid chromatography-mass spectrometry. J Proteome Res. 2011; 10: 5222-31.

52. Mayeur S, Wattez JS, Lukaszewski MA, Lecoutre S, Butruille L, Drougard A, Eberlé D, Bastide B, Laborie C, Storme L, Knauf C. Apelin controls fetal and neonatal glucose homeostasis and is altered by maternal undernutrition. Diabetes 2016; 65: 554-60

53. Xu S, Tsao PS, Yue P. Apelin and insulin resistance: Another arrow for the quiver? J Diabetes. 2011; 3: 225-31.

54. Bertrand C, Valet P, Castan-Laurell I. Apelin and energy metabolism. Front Physiol. 2015; 6: 115.

55. Gourdy P, Cazals L, Thalamas C, Sommet A, Calvas F, Galitzky M, Vinel C, Dray C, Hanaire H, Castan-Laurell I, Valet P. Apelin administration improves insulin sensitivity in overweight men during hyperinsulinaemic-euglycaemic clamp. Diabetes Obes Metab. 2017; 20: 157-64.

56. Yue $\mathrm{P}$, Jin $\mathrm{H}$, Aillaud M, Deng AC, Azuma J, Asagami T, Kundu RK, Reaven GM, Quertermous T, Tsao PS. Apelin is necessary for the maintenance of insulin sensitivity. Am J Physiol Endocrinol Metab. 2010; 298: E59-67.

57. El Wakeel MA, El-Kassas GM, Kamhawy AH, Galal EM, Nassar MS, Hammad EM, El-Zayat SR. Serum apelin and obesity-related complications in Egyptian children. Open Access Maced J Med Sci. 2018; 6: 1354-58.

58. Varela-Rodríguez BM, Pena-Bello L, Juiz-Valiña P, Vidal-Bretal B, Cordido F, Sangiao-Alvarellos S. FNDC5 expression and circulating irisin levels are modified by diet and hormonal conditions in hypothalamus, adipose tissue and muscle. Sci Rep. 2016; 6.

59. Shoukry A, Shalaby SM, El-Arabi Bdeer S, Mahmoud AA, Mousa MM, Khalifa A. Circulating serum irisin levels in obesity and type 2 diabetes mellitus. Life 2016; 68: 544-56.

60. Gizaw M, Anandakumar P, Debela T. A Review on the role of irisin in insulin resistance and type 2 diabetes mellitus. J Pharmacopuncture. 2017; 20: 235-42.

61. Cannon B, Nedergaard J. Brown adipose tissue: Function and physiological significance. Physiol Rev. 2004; 84: 277-359.

62. Zhang Y, Li R, Meng Y, Li S, Donelan W, Zhao Y, Qi L, Zhang M, Wang X, Cui T, Yang LJ. Irisin stimulates browning of white adipocytes through mitogen-activated protein kinase p38 MAP kinase and ERK MAP kinase signaling. Diabetes 2014; 63:
514-25.

63. Pardo $M$, Crujeiras AB, Amil M, Aguera Z, Jiménez-Murcia $S$, Baños R, Botella $C$, de la Torre R, Estivill X, Fagundo AB, Fernández-Real JM. Association of irisin with fat mass, resting energy expenditure, and daily activity in conditions of extreme body mass index. Int J Endocrinol. 2014; 2014.

64. Kim OY, Song J. The role of irisin in Alzheimer's disease. J Clin Med. 2018; 7: 407.

65. Elizondo-Montemayor L, Mendoza-Lara G, Gutierrez-DelBosque SG, Peschard-Franco M, Nieblas B, Garcia-Rivas G. Relationship of circulating irisin with body composition, physical activity, and cardiovascular and metabolic disorders in the pediatric population. Int J Mol Sci. 2018; 19: E3727.

66. Shi X, Lin M, Liu C, Xiao F, Liu Y, Huang P, Zeng $X$, Yan B, Liu S, Li X, Yang S. Elevated circulating irisin is associated with lower risk of insulin resistance: Association and path analyses of obese Chinese adults. BMC Endocr Disord. 2016; 16: 44.

67. Fukushima Y, Kurose S, Shinno H, Cao Thi Thu H, Tamanoi A, Tsutsumi H, Hasegawa T, Nakajima T, Kimura Y. Relationships between serum irisin levels and metabolic parameters in Japanese patients with obesity. Obes Sci Pract. 2016; 2: 20309.

68. Khalili S, Khaniani MS, Afkhami F, Derakhshan SM. NUCB2/Nesfatin-1: A potent meal regulatory hormone and its role in diabetes. Egyptian J Med Human Genet. 2017; 18: 105-09.

69. Dore R, Levata L, Lehnert H, Schulz C. Nesfatin-1: Functions and physiology of a novel regulatory peptide. J Endocrinol. 2017; 232: R45-R65.

70. Ayada C, Toru Ü, Korkut Y. Nesfatin-1 and its effects on different systems. Hippokratia 2015; 19: 4-10.

71. Zhai T, Li SZ, Fan XT, Tian Z, Lu XQ, Dong J. Circulating nesfatin- 1 levels and type 2 diabetes: A systematic review and meta-analysis. J Diabetes Res. 2017; 2017.

72. Nakata M, Manaka K, Yamamoto S, Mori M, Yada T. Nesfatin-1 enhances glucose-induced insulin secretion by promoting $\mathrm{Ca}^{2+}$ influx through L-type channels in mouse islet $\beta$-cells. Endocr J. 2011; 58: 305-13.

73. Schalla MA, Stengel A. Current understanding of the role of nesfatin-1. J Endocr Soc. 2018; 2: 1188206.

74. Yang M, Zhang Z, Wang C, Li K, Li S, Boden G, Li L, Yang G. Nesfatin-1 action in the brain increases insulin sensitivity through Akt/AMPK/TORC2 pathway in diet-induced insulin resistance. Diabetes 2012; 61: 1959-68.

75. Mierzyński R, Poniedziałek-Czajkowska E, Dłuski D, Patro-Małysza J, Kimber-Trojnar Ż, Majsterek M, Leszczyńska-Gorzelak B. Nesfatin-1 and vaspin as potential novel biomarkers for the predic- 
tion and early diagnosis of gestational diabetes mellitus. Int J Mol Sci. 2019; 20: 159.

76. Ristić-Medić D, Vučić V, Takić M, Karadžić I, Glibetić M. Polyunsaturated fatty acids in health and disease. J Serb Chem Soc. 2013; 78: 1269-89.

77. Azrad M, Turgeon C, Demark-Wahnefried W. Current evidence linking polyunsaturated fatty acids with cancer risk and progression. Front Oncol. 2013; 3: 224

78. Das UN. Long-chain polyunsaturated fatty acids and diabetes mellitus. Am J Clin Nutr. 2002; 75: 780-81.

79. Abedi E, Sahari MA. Long-chain polyunsaturated fatty acid sources and evaluation of their nutritional and functional properties. Food Sci Nutr. 2014; 2: 443-63.

80. Agostoni C. Role of long-chain polyunsaturated fatty acids in the first year of life. J Pediatr Gastroenterol Nutr. 2008; 47: S41-44.

81. Thota RN, Acharya SH, Garg ML. Curcumin and/ or omega-3 polyunsaturated fatty acids supplementation reduces insulin resistance and blood lipids in individuals with high risk of type 2 diabetes: A randomised controlled trial. Lipids Health Dis. 2019; 18: 31.

82. Imamura $\mathrm{F}$, Micha $\mathrm{R}, \mathrm{Wu} \mathrm{JH}$, de Oliveira Otto MC, Otite FO, Abioye AI, Mozaffarian D. Effects of saturated fat, polyunsaturated fat, monounsaturated fat, and carbohydrate on glucose-insulin homeostasis: A systematic review and metaanalysis of randomised controlled feeding trials. PLoS Med. 2016; 13.

83. Innis S, Novak E. Lactose: A milk-specific carbohydrate enabling homeostatic regulation of glucose and insulin (623.12). FASEB. 2014; 28.

84. Ballard O, Morrow AL. Human milk composition Nutrients and bioactive factors. Pediatr Clin North Am. 2013; 60: 49-74.

85. Singhal A, Lucas A. Early origins of cardiovascular disease: Is there a unifying hypothesis? Lancet 2004; 363: 1642-45.

86. Oddy WH. Infant feeding and obesity risk in the child. Breastfeed Rev. 2012; 20: 7-12.

87. Agostoni C, Braegger C, Decsi T, Kolacek S, Koletzko B, Michaelsen KF, Mihatsch W, Moreno LA, Puntis J, Shamir R, Szajewska H. Breastfeeding: A commentary by the ESPGHAN Committee on nutrition. J Pediatr Gastroenterol Nutr. 2009; 49: $112-25$.

88. Bode L. Human milk oligosaccharides: Every baby needs a sugar mama. Glycobiology 2012; 22: 1147-62.

89. Musilova S, Rada V, Vlkova E, Bunesova V. Beneficial effects of human milk oligosaccharides on gut microbiota. Benef Microbes. 2014; 5: 273-83.

90. Plaza-Díaz J, Fontana L, Gil A. Human milk oligo- saccharides and immune system development. Nutrients 2018; 10: 1038

91. He Y, Liu S, Kling DE, Leone S, Lawlor NT, Huang Y, Feinberg SB, Hill DR, Newburg DS. The human milk oligosaccharide 2 '-fucosyllactose modulates CD14 expression in human enterocytes, thereby attenuating LPS-induced inflammation. Gut 2016; 65: 33-46.

92. Biagi E, Quercia S, Aceti A, Beghetti I, Rampelli S, Turroni S, Faldella G, Candela M, Brigidi P, Corvaglia L. The bacterial ecosystem of mother's milk and infant's mouth and gut. Front Microbiol. 2017; 8: 1214

93. Toscano M, De Grandi R, Grossi E, Drago L. Role of the human breast milk-associated microbiota on the newborns' immune system: A mini review. Front Microbiol. 2017; 8: 2100

94. Fain JN, Gerald L. Release of interleukins and other inflammatory cytokines by human adipose tissue is enhanced in obesity and primarily due to the nonfat cells. Vitam Horm. 2006; 74: 443-77.

95. Mandrup-Poulsen T, Zumsteg U, Reimers J, Pociot F, Mørch L, Helqvist S, Dinarello CA, Nerup J. Involvement of interleukin 1 and interleukin 1 antagonist in pancreatic $\beta$-cell destruction in insulin-dependent diabetes mellitus. Cytokine 1993; 5: 185-91.

96. Garlanda C, Dinarello CA, Mantovani A. The interleukin-1 family: Back to the future. Immunity 2013; 39: 1003-18.

97. Ballak DB, Van Diepen JA, Moschen AR, Jansen HJ, Hijmans A, Groenhof GJ, Leenders F, Bufler P, Boekschoten MV, Müller M, Kersten S. IL-37 protects against obesity-induced inflammation and insulin resistance. Nat Commun. 2014; 5: 4711.

98. Rehman K, Akash MS, Liaqat A, Kamal S, Qadir MI, Rasul A. Role of interleukin-6 in development of insulin resistance and type 2 diabetes mellitus. Crit Rev Eukaryot Gene Expr. 2017; 27: 229-36.

99. Scheller J, Chalaris A, Schmidt-Arras D, Rose-John $\mathrm{S}$. The pro- and anti-inflammatory properties of the cytokine interleukin-6. Biochimica et Biophysica Acta Mol Cell Res. 2011; 1813: 878-88.

100. Bastard JP, Maachi M, van Nhieu JT, Jardel C, Bruckert E, Grimaldi A, Robert JJ, Capeau J, Hainque B. Adipose tissue IL-6 content correlates with resistance to insulin activation of glucose uptake both in vivo and in vitro. J Clin Endocrinol Metab. 2002; 87: 2084-89.

101. Carey AL, Febbraio MA. Interleukin-6 and insulin sensitivity: Friend or foe? Diabetologia 2004; 47: 1135-42.

102. Fields DA, Demerath EW. Relationship of insulin, glucose, leptin, IL-6 and TNF-a in human breast milk with infant growth and body composition. Pediatr Obes. 2012; 7.

103. Petersen AMW, Pedersen BK. The anti-inflamma- 
tory effect of exercise. J Appl Physiol. 2005; 98: 1154-62.

104. Barry JC, Shakibakho S, Durrer C, Simtchouk S, Jawanda KK, Cheung ST, Mui AL, Little JP. Hyporesponsiveness to the anti-inflammatory action of interleukin-10 in type 2 diabetes. Sci Rep. 2016; 6.

105. Dagdeviren S, Jung DY, Friedline RH, Noh HL, Kim JH, Patel PR, Tsitsilianos N, Inashima K, Tran DA, Hu X, Loubato MM. IL-10 prevents agingassociated inflammation and insulin resistance in skeletal muscle. FASEB J. 2017; 31: 701-10.

106. Hong EG, Ko HJ, Cho YR, Kim HJ, Ma Z, Tim YY, Friedline RH, Kurt-Jones E, Finberg R, Fischer MA, Granger EL. Interleukin-10 prevents dietinduced insulin resistance by attenuating macrophage and cytokine response in skeletal muscle. Diabetes 2009; 58: 2525-35.

107. Dawod B, Marshall JS. Cytokines and soluble receptors in breast milk as enhancers of oral tolerance development. Front Immunol. 2019; 10: 16.

108. Morikawa M, Derynck R, Miyazono K. TGF- $\beta$ and the TGF- $\beta$ family: Context-dependent roles in cell and tissue physiology. Cold Spring Harb Perspect Biol. 2016; 8: a021873.

109. Brown ML, Schneyer AL. Emerging roles for the TGF $\beta$ family in $\beta$-cell homeostasis. Trends Endocrinol Metab. 2010; 21: 441-48.

110. Brown ML, Kimura F, Bonomi LM, Ungerleider NA, Schneyer AL. Differential synthesis and action of TGF $\beta$ superfamily ligands in mouse and rat islets. Islets 2011; 3: 367-75.

111. Lu M, Jiang J, Wua K, Li D. Epidermal growth factor and transforming growth factor- $\alpha$ in human milk of different lactation stages and different regions and their relationship with maternal diet. Food Funct. 2018; 9: 1199-204.

112. Lee HY, Yea K, Kim J, Lee BD, Chae YC, Kim HS, Lee DW, Kim SH, Cho JH, Jin CJ, Koh DS. Epidermal growth factor increases insulin secretion and lowers blood glucose in diabetic mice. J Cell Mol Med. 2008; 12: 1593-604.

113. Schlessinger J. Ligand-induced, receptor-mediated dimerization and activation of EGF receptor. Cell 2002; 110: 669-72.

114. Ge C, Yu M, Petitte JN, Zhang C. Epidermal growth factor-induced proliferation of chicken primordial germ cells: Involvement of calcium/ protein kinase C and NFKB1. Biol Reproduc. 2009; 80: 528-36.

115. Miettinen P, Ormio P, Hakonen E, Banerjee M, Otonkoski T. EGF receptor in pancreatic $\beta$-cell mass regulation. Biochem Soc Trans. 2008; 36: 28085.
116. Bayes-Genis A, Conover CA, Schwartz RS. The insulin-like growth factor axis: A review of atherosclerosis and restenosis. Circ Res. 2000; 86: $125-30$.

117. Friedrich N, Thuesen B, Jørgensen T, Juul A, Spielhagen C, Wallaschofksi H, Linneberg A. The association between IGF-I and insulin resistance. Diabetes Care. 2012; 35: 768-73.

118. Aguirre GA, De Ita JR, de la Garza RG, CastillaCortazar I. Insulin-like growth factor-1 deficiency and metabolic syndrome. J Trans Med. 2016; 14: 3.

119. Wheatcroft SB, Kearney MT, Shah AM, Ezzat VA, Miell JR, Modo M, Williams SC, Cawthorn WP, Medina-Gomez G, Vidal-Puig A, Sethi JK. IGFbinding protein- 2 protects against the development of obesity and insulin resistance. Diabetes 2007; 56: 285-94.

120. Assefa B, Mahmoud AM, Pfeiffer AF, Birkenfeld $\mathrm{AL}$, Spranger J, Arafat AM. Insulin-like growth factor (IGF) binding protein-2, independently of IGF-1, induces GLUT-4 translocation and glucose uptake in 3T3-L1 adipocytes. Oxid Med Cell Longev. 2017; 2017.

121. Heald AH, Kaushal K, Siddals KW, Rudenski AS, Anderson SG, Gibson JM. Insulin-like growth factor binding protein-2 (IGFBP-2) is a marker for the metabolic syndrome. Exp Clin Endocrinol Diabetes. 2006; 114: 371-76.

122. Palmeira P, Carneiro-Sampaio M. Immunology of breast milk. Rev Assoc Med Bras. 2016; 62.

123. Martin CR, Ling P, Blackburn GL. Review of infant feeding: Key features of breast milk and infant formula. Nutrients 2016; 8: 279.

124. Lönnerdal B. Bioactive proteins in breast milk. J Paediatr Child Health. 2013; 49 (S1).

125. Siqueiros-Cendón T, Arévalo-Gallegos S, IglesiasFigueroa BF, García-Montoya IA, Salazar-Martínez J, Rascón-Cruz Q. Immunomodulatory effects of lactoferrin. Acta Pharmacol Sin. 2014; 35: 55766.

126. Cacho NT, Lawrence RM. Innate immunity and breast milk. Front Immunol. 2017; 8: 584.

127. Baban B, Malik A, Bhatia J, Yu JC. Presence and profile of innate lymphoid cells in human breast milk. JAMA Pediatr. 2018; 172: 594-96.

128. Cabinian A, Sinsimer D, Tang M, Zumba $O$, Mehta H, Toma A, Sant'Angelo D, Laouar Y, Laouar A. Transfer of maternal immune cells by breastfeeding: Maternal cytotoxic T lymphocytes present in breast milk localize in the Peyer's patches of the nursed infant. PLoS One. 2016; 11: $\mathrm{e} 0156762$.

129. Newman J. How breastmilk protects newborns. Available online from http://www.breastfeedingonline.com/HowBreastmilkProtectsNewborns.pdf 